\title{
Correction to: Shaping Natural History and Settler Society
}

\author{
Tanja Hammel
}

\section{Correction to:}

T. Hammel, Shaping Natural History and Settler Society, Cambridge Imperial and Post-Colonial Studies Series, https://doi.org/10.1007/978-3-030-22639-8

The book was inadvertently published with errors. The below listed changes have been made in this book.

1. Copyright holder was updated from "The Editor(s) (if applicable) and The Author(s), under exclusive licence to Springer Nature Limited" to "The Editor(s) (if applicable) and The Author(s)".

2. The below sentence is included in the Acknowledgement section: "This book was made available open access through funding by the Swiss National Science Foundation grant: 10BP-2_186623."

3. Incorrect image was placed for Figure 2.2 in Chapter 2 which has now been included correctly as follows:

The updated version of the book can be found at https://doi.org/10.1007/978-3-030-22639-8

https://doi.org/10.1007/978-3-030-22639-8_2

(C) The Author(s) 2020

T. Hammel, Shaping Natural History and Settler Society, Cambridge Imperial and Post-Colonial Studies Series, https://doi.org/10.1007/978-3-030-22639-8_11 


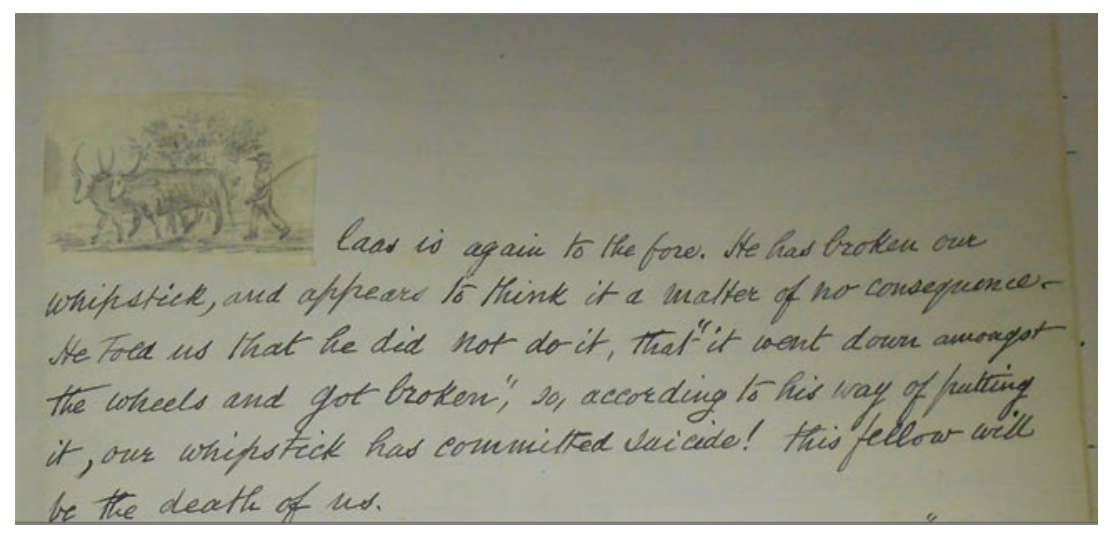

Fig. 2.2 Barber's pencil sketch of Klaas. Initial of Chapter 4 for 'K', MS 10560. (c) Cory Library. All rights reserved) 